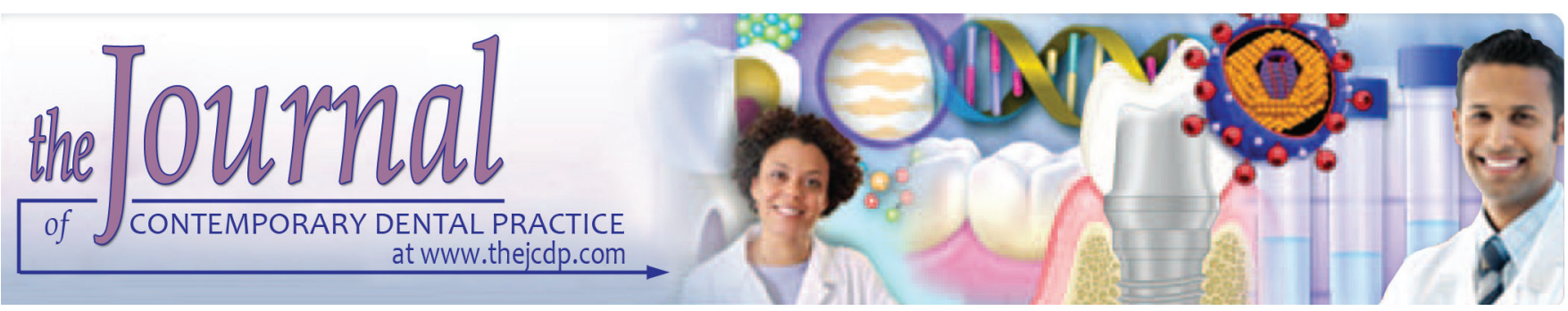

\title{
Apical Extrusion of Intracanal Bacteria following use of Two Engine-driven Instrumentation Techniques: An in vitro Study
}

${ }^{1}$ Niyaz Mohammed, ${ }^{2} \mathrm{MC}$ Noushad, ${ }^{3} \mathrm{Biji}$ Balan, ${ }^{4} \mathrm{~N}$ Dhanesh, ${ }^{5}$ Nishi Jayasheelan, ${ }^{6}$ Vanita D Revankar

\begin{abstract}
Aim: The aim of the present study was to compare in vitro the amount of debris extruded apically from extracted teeth, using Twisted files and ProTaper rotary during two different instrumentation systems.

Materials and methods: Forty-five human single-rooted mandibular premolar teeth were randomly divided into three groups and contaminated with Enterococcus faecalis. The teeth in experimental groups were instrumented until reaching the working length with ProTaper rotary instruments and Twisted files with XSmart and XSmart Dual groups. Debris extruded from the apical foramen was collected into glass vials and the amount of bacteria was calculated. The data obtained were analyzed using Kruskal-Wallis one-way analysis of variance and Mann-Whitney $U$ tests, with $p=0.05$ as the level for statistical significance.
\end{abstract}

Results: The XSmart Dual group extruded comparatively lesser bacteria compared to the XSmart group. Lesser amount of bacterial extrusion was seen when Twisted files were used compared to the ProTaper files $(p<0.05)$.

Conclusion: Under the circumstances of this in vitro study, it can be concluded that all instrumentation techniques produced measurable apical extrusion of debris. So, it is upon the practitioner to decide which system best fits their individual needs

\footnotetext{
${ }^{1-3}$ Department of Conservative Dentistry and Endodontics Kannur Dental College, Kannur, Kerala, India

${ }^{4}$ Department of Pedodontics and Preventive Dentistry, Kannur Dental College, Kannur, Kerala, India

${ }^{5}$ Department of Conservative Dentistry and Endodontics Yenepoya Dental College, Mangaluru, Karnataka, India

${ }^{6}$ Department of Conservative Dentistry and Endodontics, The Vinayaka Mission's Sankarachariyar Dental College, Salem Tamil Nadu, India

Corresponding Author: Niyaz Mohammed, Department of Conservative Dentistry and Endodontics, Kannur Dental College, Kannur, Kerala, India, Phone: +918281588171, e-mail: niyazbond@gmail.com
}

and their level of skill and experience that will provide the best possible endodontic care for our patients.

Clinical significance: The newer instrument designs, including noncutting tips, different cross sections, radial lands, and variable tapers, are better for the clinicians to improve working safety, to reduce the working time, and to create a greater flare within the preparations.

Keywords: Engine-driven, Extruded debris, ProTaper, Twisted files.

How to cite this article: Mohammed N, Noushad MC, Balan B, Dhanesh N, Jayasheelan N, Revankar VD. Apical Extrusion of Intracanal Bacteria following use of Two Engine-driven Instrumentation Techniques: An in vitro Study. J Contemp Dent Pract 2016;17(11):939-942.

Source of support: Nil

Conflict of interest: None

\section{INTRODUCTION}

A major objective in endodontic treatment is to clean and shape the root canal system. In this process, dentinal chips, pulpal tissue fragments, necrotic tissues, microorganisms, and intracanal irrigants can be extruded through the apical foramen. This is a concern as material extruded through the apical foramen can be linked to post-instrumentation pain and a "flare-up."1

The inter-appointment flare-up is a true complication characterized by the development of pain, swelling or both, which commences after few hours or days of root canal procedures and is of adequate severity to require a nonscheduled visit for emergency treatment. ${ }^{2}$ Occurrence of mild postoperative pain is quite common even when the procedure has followed acceptable standards, and it should be anticipated and expected by the patients. However, an inter-appointment flare-up has been shown to be an unusual occurrence. The factors that cause interappointment flare-ups comprise mechanical, chemical, 
or microbial injury to the pulp-periradicular tissues. ${ }^{3}$ All the preparation instruments and techniques have been shown to be associated with the extrusion of infected debris, even when the preparation is maintained short of the apical foramen. ${ }^{1}$ It was shown that the stepback technique produced greater debris than the engine-driven techniques and the balanced force technique. ${ }^{4}$

Over the last decade, root canal procedure with engine-driven nickel-titanium (NiTi) instrumentation has become very popular. More recently, newer instrument designs, including noncutting tips, different cross sections, radial lands, and variable tapers, have been introduced to improve working safety, to reduce the working time, and to create a greater flare within the preparations. ${ }^{1}$

Devices have been developed that incorporate an electronic apex locator with an electric handpiece for preparation of the root canal. The rotation of the NiTi files stops as the point estimated to be the end of the root canal is reached. Hence, these apex-locator-controlled handpieces eliminates the need to maintain working length with multiple files and the need for a reference point on the tooth. ${ }^{5}$

\section{MATERIALS AND METHODS}

\section{Selection and Preparation of Teeth}

Freshly extracted 40 human single-rooted mandibular premolar teeth with closed apices and curvatures less than $10^{\circ}$ were selected. All samples were controlled using digital radiographs in buccal and proximal directions to rule out multiple canals. Teeth with open apices and calcification were excluded. The teeth were then cleaned of soft tissue remnants and debris and were stored in physiological saline solution at $+4^{\circ} \mathrm{C}$ until necessary. An endodontic access cavity was prepared (Endo Access Bur, Dentsply Maillefer, Ballaigues, Switzerland) in a high-speed handpiece. Pulp chambers were accessed and a reservoir is created for the contamination of the root canals with a suspension of Enterococcus faecalis. Pulp remnants were then extirpated with a fine barbed broach, with care taken not to push the broach through the apical foramen.

\section{Test Apparatus}

A rubber stopper was adjusted for use by using a heated instrument and creating a hole through the center of each vial. Under pressure the tooth was inserted into a rubber stopper, which was fixed to the cementoenamel junction by means of cyanoacrylate. The apical portion of the root was suspended within the vial, which acted as a collecting container for apical material that is evacuated through the root foramen. A 27-gauge needle was bent and forced alongside the rubber stopper to use as a cannula for drainage, balance air pressure inside and outside the vials, and also as an electrode for the electronic working length determination while instrumentation. Two coats of nail varnish was then applied to the external surface of all roots. Rubber stopper with the tooth was then fixed into the mouth of the vials. Glass vials were filled with $0.9 \%$ saline solution. Ahead of the experiment, a hole was created in the nail varnish which covered the apical foramen with the help of a size $15 \mathrm{~K}$-file. In this procedure, only $1 \mathrm{~mm}$ of instrument was extruded. In this method a standard size of foramen and apical patency was achieved. The tooth-rubber stopper-needle unit was fitted into the mouth of the vial. The entire model system was then sterilized in ethylene oxide gas for a 12-h cycle using the anprolene and $74^{\circ} \mathrm{C}$ gas sterilizer.

\section{Contamination with Enterococcus faecalis}

A pure culture of E. faecalis (ATCC 29212) was used to contaminate the root canal system. A suspension was prepared by adding $1 \mathrm{~mL}$ of a pure culture of E. faecalis, grown in brain-heart infusion broth for 24 hours, to fresh brain-heart infusion broth. $10 \mu \mathrm{L}\left[1.5 \times 10^{8}\right.$ colony forming unit (CFU)] of the suspension was used to contaminate the root canals using sterile micropipette in a laminar airflow cabinet to prevent any airborne contamination, and a size $10-\mathrm{K}$ file was used to carry the bacteria along the length of the canals. The contaminated roots were then dried in an incubator at $37^{\circ} \mathrm{C}$ for 24 hours. Glass vials were then entirely filled with sterile $0.9 \% \mathrm{NaCl}$ solution.

\section{Methodology}

The selected teeth were divided into three groups:

\section{Group I: XSmart group}

Ia: ProTaper files

Ib: Twisted files

\section{Group II: XSmart Dual group}

IIa: ProTaper files

IIb: Twisted files

\section{Group III: Uninstrumented group (control)}

Eight teeth were assigned to each of the groups.

\section{Root Canal Preparation}

All root canal preparations were completed by endodontic handpiece at low speed (300 rpm). The operator was shielded from looking at the root apex during the instrumentation procedure by rubber dam that obscured the vail. 
A $2 \mathrm{~mL}$ of $2.5 \% \mathrm{NaOCl}$ was used in each root canal for irrigation and at the end of instrumentation. Final irrigation was then accomplished with $5 \mathrm{~mL}$ of $2.5 \%$ $\mathrm{NaOCl}$ solution. The irrigant was delivered by disposable plastic syringe with an attached 27-gauge needle that had been placed down the canal till slight resistance was felt.

The instrumentation in the study was done using the following sequence:

\section{XSmart Group}

The working length in this group was first determined using an electronic apex locator. The teeth in the group were then prepared using both ProTaper files and Twisted files. Using the manufacturer's instructions, the files were used in a gentle in-and-out motion using crowndown technique. Instruments were withdrawn when resistance was felt and changed for the next instrument.

Once the instrument had negotiated to the end of the canal and had rotated freely, it was removed.

\section{XSmart Dual Group}

Instrumentation in this group was done with the dualmode switched on in the endo-motor, i.e., the apex location function drives the endo-motor. The files were then used using crowndown technique. When the apex was reached the files automatically autoreversed in the group.

\section{Control Group}

After contamination and apical perforation, 8 teeth were chosen and maintained in the test medium. Subsequently, $0.1 \mathrm{~mL} \mathrm{NaCl}$ was taken from the experimental vials for evaluating the bacteria, and then incubated in a brainheart agar. Bacterial colonies were counted and the results were given as $\mathrm{CFU}$.

\section{Statistical Analysis}

The data obtained were analyzed using Kruskal-Wallis one-way analysis of variance and Mann-Whitney $\mathrm{U}$ tests. The level of statistical significance was kept at $\mathrm{p}=0.05$.

\section{RESULTS}

Comparison of the mean number of extruded bacteria between XSmart-Control and XSmart Dual-Control showed statistically significant difference. The XSmart Dual group extruded comparatively lesser bacteria when compared to the XSmart group. Lesser amount of bacterial extrusion was seen when Twisted files were used compared to the ProTaper files. The mean amount of bacterial extrusion is given in Tables 1 and 2.
Table 1: Mean bacterial extrusion value between XSmart and XSmart Dual groups

\begin{tabular}{llll}
\hline Groups & Total & Mean $(C F U ~ m L)$ & $S D$ \\
\hline XSmart & 16 & 8.8544 & 1.15 \\
XSmart Dual & 16 & 7.6581 & 1.17 \\
Control & 8 & 0.5650 & 0.09 \\
\hline
\end{tabular}

SD: Standard deviation

Table 2: Mean bacterial extrusion value between ProTaper and Twisted file systems

\begin{tabular}{llll}
\hline Groups & Total & Mean $(\mathrm{CFU} m L)$ & $S D$ \\
\hline ProTaper & 8 & 9.26 & 1.16 \\
Twisted & 8 & 8.44 & 1.05 \\
\hline
\end{tabular}

SD: Standard deviation; CFU: Colony forming unit

\section{DISCUSSION}

The primary objective of the study was to assess the apical extrusion of bacteria as a result of canal shaping by two different engine-driven instrumentation technique. In this study, mandibular premolar teeth were carefully selected according to tooth type, working length, canal size, and canal curvature. Common to all techniques were the amount and type of the irrigant and the operator. During the experiment, the lip clip was connected to needle, and saline solution was used as a conducting medium. Working lengths were determined $0.5 \mathrm{~mm}$ short of the apical foramen for all the teeth. Also, the size of master apical instrument was kept constant, the tip diameter of a ProTaper F2 instrument and Twisted file at 25.

It is well documented in the literature that contaminated as well as noncontaminated materials can cause an inflammatory reaction when it was forced apically during root canal preparation. Therefore, every effort should be exerted to limit the periapical extrusion of intracanal materials during treatment. ${ }^{6}$

The extrusion produced by the various techniques was expected, because it is considered to be a problem for every canal instrumentation methods. The results of this study demonstrated that the instrumentation techniques and the filing systems used created apically extruded bacteria ex vivo.

Many factors affect the amount of extruded intracanal materials, such as the instrumentation technique, instrument type and size, preparation endpoint, and irrigation solution. ${ }^{8}$ The ProTaper system used caused a larger amount of extruded bacteria compared to Twisted files. It can be speculated that a faster, aggressive system with its characteristic design feature that removes a substantial amount of dentin in a shorter period of time is unable to displace the debris coronally, with the same efficiency with which it cuts, thus posing a risk of increased apical extrusion of debris. Also, the long pitch design of the ProTaper instruments can cause a greater amount of debris to be extruded. ${ }^{9}$ 
In Twisted files, the files do not screw in, but rather efficiently shapes dentin and channels the debris out of the canal. This debris channeling is a function of the flute width and depth becoming larger moving from the tip to the handpiece end of the file. In essence, there is more room to hold the debris in the flutes until they can be wiped out than would be present in a highly symmetrical cross design in regard to flute width and depth.

In this study, the crowndown technique was used. As greater number of microorganisms are present in coronal third, initial preparation helps to reduce microorganisms that may be pushed apically. ${ }^{10}$ Also, on early flaring of the coronal part, the preparation may improve the control of instruments during preparation of the apical third of the canal. ${ }^{11,12}$

Enterococcus faecalis was chosen as the bacteriologic marker. It is a nonfastidious, easy-to-grow aerobic bacterium of significant clinical importance. Enterococcus faecalis, unlike other bacteria, has been reported to survive and successfully thrive alone. ${ }^{13,14}$

\section{CONCLUSION}

Under the circumstances of this in vitro study, it can be concluded that all instrumentation techniques produced measurable apical extrusion of debris. However, the XSmart Dual system resulted in lesser bacterial extrusion compared to the XSmart rotary system. Also, the Twisted series of files extruded comparatively lesser bacteria than the ProTaper system. So, it is dependent on the practitioner to decide which system best fits their individual needs, and their level of skill and experience that will provide the best possible endodontic care for patients.

\section{REFERENCES}

1. Er K, Sümer Z, Akpinar KE. Apical extrusion of intracanal bacteria following use of two engine-driven instrumentation techniques. Int Endod J 2005 Dec;38:871-876.
2. Ghivari SB, Kubasad GC, Chandak MG, Akarte NR. Apical extrusion of debris and irrigant using hand and rotary systems: a comparative study. J Conserv Dent 2011 Apr-Jun;14(2): 187-190.

3. Siqueira JF Jr. Microbial causes of endodontic flare-ups. Int Endod J 2003 Jul;36(7):453-463.

4. Zarrabi MH, Bidar M, Jafarzadeh $\mathrm{H}$. An in vitro comparative study of apically extruded debris resulting from conventional and three rotary (Profile, Race, FlexMaster) instrumentation techniques. J Oral Sci 2006 Jun;48(2):85-88.

5. Sakkir N, Asifulla M, Chandra V, Idris M, Razvi SF, Geeta IB. In vitro evaluation of the accuracy of five different electronic apex locators. Saudi Endod J 2015 Sep-Dec;5(3):177-181.

6. Ruiz-Hubard EE, Guttman JL, Wagner MJ. A quantitative assessment of canal debris forced periapically during root canal instrumentation using two different techniques. J Endod 1987 Dec;13(12):554-558.

7. Vande Visse IE, Brillant JD. Effect of irrigation on the production of extruded material at the root apex during instrumentation. J Endod 1975 Jul;1(7):243-246.

8. Salzgeber RM, Brilliant JD. An in vivo evaluation of the penetration of an irrigating solution in root canals. J Endod 1977 Oct;3(10):394-398.

9. Tasdemir T, Er K, Çelik D, Aydemir H. An in vitro comparison of apically extruded debris using three rotary nickel-titanium instruments. J Dent Sci 2010 Sep;5(3):121-125.

10. Shovelton DS. The presence and distribution of microorganisms within nonvital teeth. Br Dent J 1964 Aug;117(3):101-107.

11. Goerig AC, Michelich RJ, Schultz HH. Instrumentation of root canals in molars using the step-down technique. J Endod 1982 Dec;8(12):550-554.

12. Dhingra A, Mangat $P$, Miglani A, Kalkhande S, Bhullar HK. To evaluate the effect of two passive ultrasonic irrigation methods on removal of dentin debris from root canal systems using computational fluid dynamics study model. Int J Contemp Dent Med Rev 2014;2014:011214. doi:10.15713/ins. ijcdmr.20.

13. Dahlen, G; Haapasalo, M. Microbiology of apical periodontitis. In: Orstavik D, Pitt Ford TR, editors. Essential endodontology: prevention and treatment of apical periodontitis. 1st edn. Oxford: Blackwell Sciences Ltd; 1998. p. 106-125.

14. Mallick R, Mohanty S, Behera S, Sarangi P, Nanda S, Satapathy SK. Enterococcus faecalis: a resistant microbe in endodontics. Int J Contemp Dent Med Rev 2014;2014:011114. doi:10.15713/ins.ijcdmr.5 